\title{
As livrarias de Caxias do Sul (RS) e a concorrência das vendas através da internet
}

\section{Book stores in the City of Caxias do Sul and the competition of online sales}

\author{
Tales Giovani Armiliato* \\ Universidade de Caxias do Sul \\ Caxias do Sul, Rio Grande do Sul, Brasil \\ João Claudio Arendt** \\ Universidade de Caxias do Sul \\ Caxias do Sul, Rio Grande do Sul, Brasil
}

Resumo: Este artigo tem como objetivo investigar se a venda de livros através da internet diminuiu a procura pelo produto nas livrarias de rua em Caxias do Sul (RS). Além disso, investiga em que medida os livreiros estão se adaptando à expansão das vendas no formato digital, como os e-books. Para tanto, inicialmente, realizou-se uma revisão histórica sobre os formatos do livro e sua comercialização ao longo do tempo, tomando como base Escarpit (1976), Chartier (1998), Mello (2002), Moraes (2006) e Darnton (2010). Em seguida, aplicou-se um pequeno questionário a livreiros de dez estabelecimentos localizados no centro da cidade, cujos resultados, após a análise, são trazidas a público neste trabalho.

Palavras-chave: Livrarias. Caxias do Sul. Internet. E-book.

\begin{abstract}
This article has as objective to investigate if the sale of books online has been decreasing the search for the product in the book trade in the city of Caxias do Sul (RS). Besides, it also investigated how book traders are adapting to the expansion of sales in the virtual format, like e-books. For so, initially, a historical review is performed about book's forms and it trading through times, based on Escarpit (1976), Chartier (1998), Mello (2002), Moraes (2006) and Darnton (2010). As follows, a questionnaire was applied to book traders from ten establishments located downtown, and the results, after analyses are shown in this research.
\end{abstract}

Keywords: Book stores. Caxias do Sul. Internet. E-book.

\section{INTRODUÇÃO}

As formas de produção e comercialização do livro têm sofrido rápidas mudanças nas últimas décadas, procurando adaptar-se ao mercado cada vez mais competitivo. $\mathrm{O}$ próprio material utilizado para a confecção de uma capa ou o corpo interno do livro é constantemente revisto, para que sua produção seja simplificada e se consigam atingir percentuais que possam tornar a venda mais expressiva ou competitiva nas livrarias e, até mesmo, em papelarias e outros estabelecimentos comerciais. A cadeia produtiva também sente a interferência da globalização da economia com oportunidades de compras

* Doutorando em Letras da Universidade de Caxias do Sul, Caxias do Sul, RS. E-mail: talesgiovani@terra.com.br.

** Universidade de Caxias do Sul, Caxias do Sul, RS, Brasil. E-mail: jcarendt@ucs.br. 
estendidas por praticamente todo o segmento editorial, o que é uma espécie de disputa interna das próprias editoras, visando à comercialização do livro. A adoção de novos paradigmas estabelece o surgimento de formas de atuação que não se restringem apenas ao meio físico, como livrarias, em endereços físicos, mas também pela internet, com a disponibilidade de materiais e obras virtuais (e-books e PDFs), ampliando a procura do melhor preço.

Quando o consumo do livro tem a possibilidade de não se restringir apenas a uma posição geográfica, mas à amplidão do mundo virtual, o comércio eletrônico do livro, do ponto de vista tecnológico, pode influenciar também as práticas de consumo do livro no cotidiano da sociedade. Portanto, o impacto no consumo do livro comercializado através da internet abre caminho para investimentos de empresas mundiais na construção de softwares que possam dar visibilidade à comercialização do livro pela rede mundial de computadores, sem que o leitor precise sair de casa.

Dessa forma, avaliando o cenário de comercialização do livro, acolhe-se a motivação principal deste trabalho, que visa a analisar o comércio livreiro de Caxias do Sul, no contexto da concorrência de vendas através da internet, depois de sua implantação, em 1995, no Brasil. A pesquisa envolve 10 livreiros do centro da cidade, por meio de entrevista com questões semiestruturadas.

\section{A ESCRITA E A DIFUSÃO DO LIVRO}

A escrita surgiu entre os sumérios, cerca de 3.000 a.C., na Mesopotâmia. Depois, em torno de 1.500 a.C., ocorreu o seu aparecimento na China. No início, os sumérios estilizaram os seus desenhos, os quais tentavam representar os sons da linguagem falada. Eles instauraram a escrita silábica e desenvolveram a escrita cuneiforme, ou seja, uma série de símbolos na forma de cunhas e com menos caracteres. Outros registros de mensagens foram aparecendo com a evolução da escrita: na pedra e em outros materiais como o tijolo de barro cozido ou a argila, no papiro (inventado pelos egípcios e que era facilmente transportável), no pergaminho (utilizado para editar os primeiros livros), até chegar no papel e, atualmente, na tela do computador e do smartphone.

A escrita esteve sempre ligada aos grupos sociais que detinham o poder, pois eram esses que registravam, decodificavam (leitura de códigos) e transmitiam as mensagens escritas. Essa responsabilidade foi, em parte, dos escribas, no Egito, e da Igreja, na Idade Média. De acordo com Martins,

A história da cultura terá motivos para distinguir as idades da Idade Média, mas não a história do livro, que o encara não como veículo literário, mas como coisa. Ora, qualquer que seja o grau de adiantamento popular, seja embora praticamente nula a circulação do livro, como de fato era, e nulo o seu manuseio fora dos reduzidos componentes da classe clerical, nem por isso ele deixou de existir em toda a sua plenitude, como livro, ligado, por um lado, através do pergaminho, o papiro ao papel, e, por outro lado, através das novas técnicas, o texto manuscrito ao texto impresso. Além disso, ainda que não os difundisse com a facilidade e na quantidade a que o livro moderno nos acostumou, o livro medieval conservou os conhecimentos, 
guardou-os para a Renascença, hibernou-os nos conventos, e preparou, em consequência, sem o saber e, em certo sentido, sem o querer, o movimento intelectual que substituiria a tábua medieval de valores. A Renascença não teria sido possível, no que concerne às obras escritas, se a Idade Média não tivesse possuído esses enormes silos que foram as suas bibliotecas monásticas, universitárias e particulares (MARTINS, 1996, p. 96).

Do surgimento da escrita até a idealização do livro, apareceram novas descobertas que chegaram a meados de 1450, quando o alemão Johannes Gutenberg desenvolveu uma prensa móvel que revolucionou o mundo da tipografia, forma eficiente de reproduzir livros e jornais. Conhecido como o inventor da imprensa, Gutenberg tinha forte inclinação para a leitura desde os seus tempos de infância, quando lia os livros manuscritos da época, feitos por monges e escribas, e que demoravam meses para ficarem prontos e tinham custo elevado. Chartier explica que o desenvolvimento da técnica da tipografia tornou possível a edição de vários livros que passaram a ser acessíveis a um público mais vasto:

Em meados da década de 1450, só era possível reproduzir um texto copiando-o à mão, e de repente uma nova técnica, baseada nos tipos móveis e na prensa transfigurou a relação com a cultura escrita. $O$ custo do livro diminui através da distribuição das despesas pela totalidade da tiragem muito modesta, aliás, entre mil e mil e quinhentos exemplares. Analogamente, o tempo de reprodução do texto é reduzido graças ao trabalho da oficina tipográfica (CHARTIER, 1998, p. 7).

Com o passar dos séculos e das descobertas já mencionadas, o livro popularizou-se definitivamente, tornando-se mais acessível à população em geral, devido à enorme redução dos seus custos na produção. Surgiram, com ele, novas ocupações: o editor, o revisor, o catalogador e o bibliotecário. O livro tornou-se um dos mais importantes meios de difusão da informação e do conhecimento. Ele pode armazenar informação e é de acesso relativamente fácil, podendo ser emprestado e comprado.

\section{OS LIVROS E SUA COMERCIALIZAÇÃO}

É nos séculos XIX e XX que o planeta passou por uma verdadeira revolução industrial. Em 1814, surgiram a primeira estrada de ferro e, em 1824, a primeira turbina hidráulica. Conforme Martins (1996, p. 227), “o século XIX é um grande criador de livros, tanto no que concerne à invenção espiritual quanto no que se refere ao desenvolvimento material da tipografia". Entretanto, as informações sobre a aquisição de livros no BrasilColônia permanecem desencontradas. Segundo historiadores, a informação é de que praticamente ainda não existiam livrarias em fins do século XVIII. Porém, Lord Macartney, que esteve no Rio de Janeiro em 1793, confessou, à época, que duas livrarias vendiam livros religiosos e de medicina. Em contrapartida, para Moraes: 
Os Almanaques do Rio de Janeiro, feitos por Antônio Durante Nunes, para os anos de 1792 e 1794 mencionam uma única. Existiam duas em 1799. É um quase nada. Entretanto, existe documento inédito até hoje que nos dá uma visão diferente sobre o número de pessoas ligadas ao livro no Rio de Janeiro em meados do século XVIII. Em 1755, os oficiais de livreiro dessa cidade requereram que lhes fossem concedidos os mesmos privilégios, isenções e liberdades que gozavam os de Lisboa (MORAES, 2006, p. 45).

Com a chegada da corte portuguesa ao Rio de Janeiro, em 1808, o comércio de livros sofreu uma modificação. Apareceram as primeiras e verdadeiras livrarias que comercializavam não só publicações brasileiras, mas também livros importados da Europa.

Essas novas livrarias anunciavam na Gazeta do Rio de Janeiro livros que tinham à venda. Usavam também um método comum na Europa, principalmente em Portugal, o de mandar imprimir, nas últimas páginas de uma obra por eles publicada uma breve lista de livros que tinham em estoque. Alguns distribuíam e mandavam pregar nas paredes lista de livros à venda nas livrarias. Os particulares que, por uma razão ou outra, desejavam desfazer-se de livros, anunciavam na Gazeta do Rio de Janeiro (MORAES, 2006, p. 50).

Entre os estrangeiros presentes no Brasil, nesse período, com atuação no ramo dos livros, estavam os franceses. É, pois, da Europa e outros países que chegaram os primeiros equipamentos específicos para a impressão de livros no país. De acordo com Hallewell (1985, p. 125), "fatores como maior disponibilidade de capital, melhoramentos técnicos - como o prelo de ferro, o papel feito à máquina e a estereotipia - além do controle rígido oficial do antigo regime francês [...] impulsionaram o aumento da produção". Para o autor, muitas editoras francesas enviavam representantes comerciais à procura de encomendas. Esse fenômeno foi denominado expansão ultramarina do comércio francês. Com matriz em Paris, uma das primeiras revendas de livros a iniciar suas atividades no Brasil foi a filial Livraria Universal, em 1827.

No início do século XX, o modelo francês desenvolvido no país e aplicado às livrarias e à atividade editorial já não acompanhava mais o desenvolvimento do Brasil. Surgiu, nesse momento, a figura de Monteiro Lobato, que não se concentrou apenas no aspecto da indústria editorial, mas também na cadeia produtiva do livro, inovando como escritor, editor e livreiro. De acordo com Martins,

Segundo pesquisa da Fundação Getúlio Vargas (Produção de Livros no Brasil, 1971), editaram-se em São Paulo 26 títulos em 1926, num total de 172.500 exemplares, número que subiu para 2.500 títulos na década seguinte. No relatório para a UNESCO, em 1969, Robert Escarpit registrou na produção brasileira 5.377 títulos em 1960e $4.812 \mathrm{em}$ 1964. Em face desses números, podemos avaliar o que significam 
os de 1994: de acordo com o divulgado pela Câmara Brasileira do Livro, o país produziu nesse ano 236 milhões de exemplares, com aumento de $6 \%$ sobre o ano anterior. O mercado editorial revelou um crescimento de $10 \%$ na produção de novos títulos: 33,5 mil em 1993, e 36,5 mil no ano seguinte, enquanto o faturamento cresceu promissoramente em 29\% (MARTINS, 1996, p. 230).

No Rio Grande do Sul, em 1879, a Gazeta de Porto Alegre publicou em suas páginas um anúncio da Loja de Livros de Gundlach, com livros escolares e obras literárias. Naquele mesmo período, a Casa de Editores Ter Bruggen, depois chamada Livraria Teuto Brasileira, disponibilizava e oferecia estoque de livros e de edições próprias, como o ensaio A Pbilosopbia no Brasil, de Silvio Romero. Em pouco tempo, tanto a Gundlach como a Teuto Brasileira, enfrentaram a concorrência das livrarias Americana, com seu estabelecimento em Pelotas, Porto Alegre e Rio Grande, além da disputa com a Universal e outras casas em Pelotas e Porto Alegre. Entrando no século XX, em plena disputa e mantendo-se fortes no mercado, as casas Gundlach, Americana e Universal foram as responsáveis pela difusão do livro, principalmente na venda de edições de obras voltadas às escolas e aos cursos superiores da época.

Um fato marcante na implantação de livrarias em solo gaúcho foi a fundação da Livraria Globo, em dezembro de 1883. Seu progresso tornou-se visível e, depois de 1929, investiu em um projeto editorial próprio, com a Revista do Globo e suas coleções. O projeto tinha à frente Henrique Bertaso e Erico Verissimo. A iniciativa e a parceria impulsionaram o mercado editorial regional e brasileiro, principalmente durante as décadas de $1930 \mathrm{e}$ 1940. No centro da capital gaúcha, além da presença da Globo, outras livrarias podiam ser encontradas: a Livraria Selbach, a Livraria do Comércio, a Livraria de João Mayer Filho e a Livraria Central, entre outras.

\section{A LIVRARIA VIRTUAL: UM NOVO JEITO DE ENCONTRAR O LIVRO}

Já passou o tempo em que vendedores visitavam a porta das casas e estabelecimentos de diferentes cidades brasileiras à procura de clientes para a comercialização de livros. Na sua maioria, à época, os títulos estavam ligados ao segmento didático, geralmente utilizado pelos alunos nas escolas. A venda por telefone e através dos catálogos também foi uma estratégia que ficou pelo caminho. Com a tecnologia cada vez mais presente na vida das pessoas e com o surgimento da internet, novas formas de comercialização de livros foram adotadas e incorporadas ao comércio livreiro. Atualmente, para se comprar um livro, não é mais necessário ir a uma loja física. A finalização da compra pode ser feita, por exemplo, por um smartphone ou iphone através das livrarias virtuais, presentes em sites próprios para a compra desses produtos. Conforme Levy (2000, p. 32), "as tecnologias digitais surgiram então como infraestrutura do ciberespaço, novo espaço de comunicação, de sociabilidade, de organização e de transação, e também como novo mercado da informação e do conhecimento".

Para se ter uma ideia, no Brasil, a Livraria Cultura, com origem em São Paulo, foi a primeira a vender livros a distância, atendendo inicialmente encomendas por telefone. 
Mais tarde, não só a Cultura, mas também outras livrarias espalhadas pelo país, iniciaram a venda de livros através da internet comercial. Essa consolidação deu-se por volta de 1999, quando o comércio livreiro, vislumbrando um novo ponto de venda, procurou garantir um espaço para a comercialização virtual dos livros.

$\mathrm{Na}$ atualidade, para muitos estudiosos da área acadêmica, as livrarias virtuais acabam apresentando maiores vantagens em relação às livrarias convencionais. Conforme Levy (2000, p. 47), "é virtual toda entidade 'desterritorializada', capaz de gerar diversas manifestações concretas em diferentes momentos e locais determinados, sem, contudo, estar ela mesma presa a um lugar ou tempo em particular". Na internet, é possível expor uma quantidade maior de obras e títulos, do que os existentes em uma livraria convencional. Outro ponto positivo está na comodidade com que a compra de um livro pode ser feita, ou seja, não é necessário que o comprador perca tempo para uma pesquisa de preços de loja em loja ou com o trânsito e as realidades impróprias para deslocamento em diversas cidades. O comprador encontra todos os produtos que julga necessário em um mesmo lugar: os sites de compras virtuais. Esse aspecto é detalhado por Melo:

Falta de tempo para o consumidor ou de títulos na praça não se consubstanciam somente nos principais critérios adotados pelos internautas na opção por livrarias virtuais. Hoje, há investimento em infraestrutura, na ergonomia da homepage, proporcionando conforto e eficácia ao internauta, bem como na segurança eletrônica das transações que podem garantir a fidelidade do consumidor. Decisões como estratégia empresarial específica para comércio eletrônico e o uso correto da tecnologia inteligente, podem significar o diferencial em relação à concorrência entre as lojas, editoras e livrarias virtuais (MELO, 2002, p. 170).

Uma das táticas utilizadas pelas empresas e grupos que comercializam livros no país através do meio virtual é a contratação de pesquisas que possam apontar o perfil dos consumidores. A iniciativa pretende conhecer os títulos mais procurados, para que os estoques sejam abastecidos e melhores preços possam ser aplicados. Em especial, em muitos sites de livrarias virtuais, com o resultado dessas pesquisas, é possível disponibilizar e comercializar os principais títulos e lançamentos, antes de chegarem às vitrinas das livrarias tradicionais. Outra resposta positiva desse procedimento é a de conhecer o que o consumidor deseja adquirir, além de livros, agregando mais lucros ao negócio.

Avanços produzidos pela indústria da tecnologia da informação têm tirado do papel inúmeros projetos com pesquisas organizadas e financiadas por grandes grupos com negócios na rede mundial de computadores. Ainda, a implementação de hardwares e softwares de eletrônicos ajudam a internet a fazer trocas eficazes de dados eletronicamente, como recorda Alves:

[...] a World Wide Web, onde tecnologias como a Hyper Text Markup Language (HTML), Extensible Markup Language (XML) e Portable Document Format (PDF) foram adotadas como padrão possibilitaram a facilidade de criar, atualizar, copiar, compartilhar, distribuir e buscar informações digitais. Esses fatores potencializaram as publicações 
digitais e influenciaram a necessidade e o desenvolvimento dos e-books readers. Nesse caso, a palavra 'livro' expressa tanto a mensagem (palavras e imagens) quanto o meio (brochura de papel), já que um sem o outro não corresponde a um livro. Sendo assim, a palavra e-book é usada para descrever o conteúdo, formato (do documento ou arquivo), reader software e reader hardware (ALVES, 2010, p. 130 - grifos no original).

Quando se fala em acesso à internet, é preciso considerar que uma grande porcentagem da população brasileira ainda não possui um computador para o ingresso na rede mundial de computadores. A falta de condições econômicas ainda impede, nesse caso, a compra de livros através da web. Mas a tendência é de que, com o tempo, o acesso seja eficaz a maior parte da população.

Voltando à disponibilidade do livro na internet, a Google e a Amazon, além de outras empresas, estão oferecendo o acesso não só ao livro físico, mas também ao conteúdo de livros na própria rede. A Amazon, por exemplo, já disponibiliza a venda de partes digitalizadas de obras pertencentes ao seu catálogo. Esse fato é fonte de conflitos constantes entre livrarias tradicionais e virtuais. A polêmica é explicitada por Darnton:

\footnotetext{
Nos últimos quatro anos, o Google vem digitalizando milhões de livros pertencentes aos acervos das principais bibliotecas de pesquisa, incluindo muitos ainda protegidos por copyright, e disponibilizando os textos para buscas on-line. Este projeto conhecido como Google Book Search, detonou uma ação judicial movida por um grupo de autores e editores alegando que a empresa estava violando seus direitos autorais. Após extensas negociações, os reclamantes e o Google chegaram a um acordo que poderá ter um efeito profundo no mundo do livro no futuro próximo. Como será esse futuro? (DARNTON, 2010, p. 21).
}

Se o questionamento de Darnton cabe para os dias atuais, é preciso entender que o principal motivo da preocupação do comércio livreiro tradicional é que empresas como a Google e Amazon realmente possuem o controle em relação ao conteúdo de milhares de títulos. Hoje, o número de pessoas que consegue copiar, distribuir e ganhar valores com conteúdo burlados de sites de livros é enorme. Basta analisar o número de processos judiciais que transcorrem em diferentes comarcas do país ou os casos divulgados pela imprensa. A utilização de meios ilícitos torna-se uma prática comum diante da própria possibilidade de se ganhar dinheiro infringindo a lei e trazendo prejuízos para a cadeia do livro.

\section{MÉTODO DE PESQUISA}

O espaço delimitado para realização desta pesquisa compreende um conjunto de livrarias localizadas no centro de Caxias do Sul, segunda maior cidade do Estado do Rio 
Grande do Sul. Entende-se aqui por livraria um estabelecimento comercial ou loja que se dedica à venda de livros.

Os estabelecimentos escolhidos para o universo deste trabalho foram sinalizados durante entrevista oral, realizada no dia 20 de julho de 2017, com o Presidente da Associação dos Livreiros Caxienses (ALCA), Cristiano Bartz Gomes. Segundo ele, na cidade, há vinte livrarias, sendo dezesseis delas associadas à ALCA. A maior parte dos estabelecimentos está localizada no centro da cidade. A Associação tem por finalidade o fomento e a difusão do livro, além de discutir e fortalecer o mercado livreiro. A entidade, com sede junto ao Centro Municipal de Cultura Dr. Henrique Ordovás Filho, é uma das organizadoras da Feira do Livro realizada todos os anos em Caxias do Sul. A intenção da união da ALCA com o poder público municipal e outros apoiadores é a de organizar pequenos eventos pouco antes do início da Feira, promovendo debates em escolas e atividades que envolvam a comercialização de livros. Para os livreiros, são previstos cursos profissionalizantes e workshops, tendo em vista a valorização da atividade. Conforme Gomes, a ideia é que a associação tenha representação junto a outras instituições, visando ao fortalecimento e ao desenvolvimento da categoria.

Esta pesquisa atinge cinquenta por cento do número de livrarias existentes em Caxias do Sul, pois foram ouvidos gerentes e coordenadores de dez dos vinte estabelecimentos. A partir de uma listagem disponibilizada pela ALCA, estabeleceu-se contato por telefone para entrevistas com os responsáveis pelos estabelecimentos. O trabalho foi executado durante a segunda quinzena de julho de 2017. O passo seguinte foi apresentar dez perguntas relacionadas à comercialização de livros nas livrarias tradicionais, as dificuldades, se existentes, com a concorrência de vendas de livros através das livrarias virtuais e, ainda, o acesso atualmente disponível ao usuário da internet a cópias de conteúdos de livros. Também foram feitas questões relacionadas ao preço entre as livrarias tradicionais e virtuais. Para evitar constrangimentos aos participantes, não serão divulgados neste estudo o endereço e o nome dos estabelecimentos, nem a identidade dos ouvidos durante a entrevista. Esse critério foi estabelecido entre pesquisadores e entrevistados.

\section{ANÁLISE DOS DADOS}

Foi constatado, durante a série de entrevistas, que a maior parte das livrarias e pontos de vendas de livros pesquisados é classificada como de micro porte: oito são de micro porte (classificação microempresa) e duas de médio porte (classificação médiaempresa). Também se procurou saber, durante a entrevista por telefone, quais tipos de livros são comercializados, e o resultado foi que, em sete delas, livros em geral; em duas, livros religiosos e, em uma, livros didáticos. Esse dado revela que a maior quantidade de livros presentes nas prateleiras das livrarias do centro de Caxias do Sul está ligada a temas gerais e/ou assuntos e temas diversos. Outra percepção é a de que, nas livrarias que trabalham com livros gerais, também são oferecidos outros serviços de vendas, como material escolar, papelaria e, em duas delas, até café. Nos estabelecimentos com vistas à 
comercialização de livros religiosos, além das obras, são encontrados à venda imagens e cartões de santos católicos.

$\mathrm{Na}$ relação de negociação de compra dos livros, entre as livrarias pesquisadas e as editoras, foi constatado que os dez estabelecimentos ouvidos não utilizam a consignação como forma de parceria de compra, ou seja, o que não é vendido ao público pelas livrarias caxienses é devolvido às editoras. Segundo os entrevistados, o preço dos livros já vem estabelecido pelas editoras. Todas as livrarias ouvidas compram seus livros dependendo da já conhecida demanda interna de procura. No caso de a venda não ser realizada, os títulos são classificados para comercialização em feiras, promoções e até em divulgação do estabelecimento durante atividades culturais. Em relação a uma das livrarias pesquisadas, especializada na venda de livros didáticos, essa negociação casada com as editoras através da consignação também não é formalizada, pois, na visão do seu gestor, muitas escolas estão comercializando livros didáticos diretamente com os alunos. As escolas adquirem-nos nas editoras, fato que para as livrarias desse gênero é uma negociação muito negativa.

Com o objetivo de fazer uma análise entre o desenvolvimento do comércio livreiro em Caxias do Sul e a venda de livros físicos através da internet no Brasil, foi questionado, nas perguntas orais, se a utilização da internet como um canal de vendas de títulos tem diminuído a compra de livros nas livrarias tradicionais. Das dez livrarias, seis apontaram uma diminuição na venda de livros físicos, o que representa entre vinte e trinta por cento de queda no faturamento total no final do mês, enquanto que quatro delas, que possuem lojas em outras cidades e estados também com plataformas virtuais (livrarias virtuais), afirmaram que a comercialização pela internet apenas agregou valor ao número de vendas, tornando-se mais um espaço de comercialização com foco no consumidor que está identificado com as compras on-line. Para alguns livreiros que atuam nas lojas físicas, no entanto, isso é considerado um verdadeiro absurdo. Um dos entrevistados, por exemplo, queixou-se que algumas livrarias virtuais e mesmo redes de livrarias virtuais fazem promoções que baixam os preços de tal forma, que uma livraria física, uma loja de rua, por exemplo, dificilmente consegue acompanhar.

Em relação à venda do livro com conteúdo virtual, o e-book, todos os gestores das livrarias ouvidas confirmam que não existe nenhuma diminuição no número de vendas das livrarias tradicionais presentes no centro da cidade, mesmo quando a procura do leitor também é por cópias de conteúdos de livros (PDFs) na internet. Eles foram enfáticos em afirmar que a maioria dos clientes das lojas ainda procura pelo livro físico como opção de leitura. Conforme os livreiros, o público de Caxias do Sul e região ainda não se adaptou à leitura de obras através da tela dos computadores, dos notebooks ou dos tablets, por exemplo. Todos foram unânimes em dizer que isso nunca deverá acontecer integralmente, pois o livro físico possui atrativos que lhe são próprios, desde o toque na capa, até o folhear das páginas. Muitos citaram o 'cheiro do livro' como forma de apelo de compra pelo livro físico.

Outro dado que chama a atenção na pesquisa é que das dez livrarias pesquisadas, quatro não possuem um endereço eletrônico na internet (site), o que segundo seus proprietários deve-se aos custos de produção, manutenção e ao seu foco de vendas, que 
não é através da internet. Por outro lado, todas as lojas ouvidas estão com páginas no Facebook. Das livrarias presentes na pesquisa, seis têm origem local e quatro são filiais provindas de outras cidades e estados brasileiros. Das livrarias locais, apenas duas vendem livros físicos através da internet, mas o percentual de pedidos é considerado baixo pelos proprietários, pois os clientes têm a tendência de visitarem as prateleiras da livraria tradicional no dia a dia. Se a livraria não possui o título procurado, é feita a encomenda do livro físico para o cliente.

Outro questionamento realizado na pesquisa aos livreiros caxienses apontou para o seu interesse e acompanhamento das ações e propostas do governo federal sobre a política de incentivo à leitura e à venda do livro. De dez livreiros ouvidos, dois deles disseram não acompanhar as ações governamentais voltadas ao livro. Por outro lado, oito entrevistados manifestaram que atualmente são péssimas as ações adotadas pelo governo federal de incentivo à leitura. Para esses livreiros, talvez esse seja um dos principais fatores para que o mercado de atuação na venda física do livro esteja em crise. Em resposta direta, livreiros avaliaram como negativas as ações governamentais por causa da falta de pessoas preparadas dentro do próprio governo e, principalmente, do Ministério da Educação para pensar a educação e, essencialmente, as políticas públicas de incentivo à leitura e ao livro em suas mais diversas categorias. Segundo os livreiros, existem mais pessoas envolvidas com a política governamental, do que com a defesa da leitura e dos livros, do futuro das livrarias e dos livreiros.

A pesquisa também questionou se faltam meios de mobilização dos próprios livreiros e livrarias locais no sentido de conjugarem forças através de associações, sindicatos e organizações que defendam o livro e os estabelecimentos de venda, especialmente a física. Todos os livreiros apontaram que existem entidades organizadas que lutam pelo livro e por outras formas para que o setor prospere. É o caso da já citada Associação dos Livreiros Caxienses (ALCA), da qual todos os entrevistados são associados. Entretanto, na visão de cada um, existe uma falta de conexão entre todas as entidades representativas do livro e dos livreiros no estado e no país. Para a maioria dos entrevistados, sete deles, essas entidades não dialogam, pois todos buscam atingir seus objetivos de forma isolada. Assim, o mercado do livro como um todo perderia força e competitividade no momento de decidir e cobrar das esferas governamentais planos de salvaguarda do livro, com ações mais eficazes e consistentes, como, por exemplo, a mudança de leis e projetos que apenas são realizados se a categoria tivesse força junto ao Congresso Nacional.

Em relação a ações de mobilização para a venda e promoção do livro em Caxias do Sul, todos os ouvidos na pesquisa fizeram questão de lembrar o episódio envolvendo a ALCA e a Prefeitura Municipal, em 2016, quando o prefeito da época, juntamente com a Secretaria Municipal da Cultura, decidiu transferir a Feira do Livro anual da cidade, que sempre fora realizada na Praça Dante Alighieri, no coração da cidade, para a Praça das Feiras, espaço fora do eixo central. Segundo os entrevistados, em momentos como o da Feira do Livro, os livreiros e o poder público municipal deveriam estar unidos, pensando na difusão do livro, fato que naquele momento não teria acontecido por parte dos gestores públicos. De acordo com Gomes, naquele ano, 
O público foi menor do que em outros anos. Nosso ideal não era movido por uma questão comercial, mas para preservar o que seria melhor, naquele momento, para a continuidade da feira. A falta de diálogo na defesa do livro deve começar na nossa casa, em Caxias do Sul. As políticas e ações voltadas ao livro são necessárias para que a cultura da cidade cresça cada vez mais e todos, juntos, possamos comemorar nossa maior festa: a cultura da leitura e do livro (ENTREVISTA ORAL, GOMES, 2017).

Outra questão da pesquisa também provocou os livreiros para assuntos que hoje são debatidos em outras nações, em relação ao futuro do livro físico, tradicionalmente encontrado nas prateleiras das livrarias. Na França, por exemplo, chegou-se a pensar em um preço único ao livro para evitar a concorrência desleal. Questionados a respeito disso, seis livreiros disseram que isso poderia ser uma opção para o Brasil, enquanto quatro não souberam responder. Dos dez livreiros, quatro apontaram que essa discussão feita na França já existe na Câmara dos Deputados, entretanto, o assunto não iria adiante pela falta de mobilização da própria categoria e por depender de parlamentares e políticos que somente tocam no assunto em tempo de eleições.

Seguindo uma linha cronológica de como poderá ser o futuro do livro, em especial as vendas dos livros físicos nas livrarias, foi colocada aos entrevistados a informação de que, segundo pesquisadores e estudiosos americanos, o mercado livreiro estaria morrendo. Para os dez livreiros, essa é uma informação que pode se referir ao mercado americano, mas não ao brasileiro. Conforme eles, o mercado americano é diferente do brasileiro, já que aqueles estariam à frente dos países da América Latina, incluindo o Brasil, no que diz respeito ao acesso à internet. Eles também apontaram que a cultura do americano é mais voltada à atividade virtual, desde a compra, até as relações de troca de informações. Na visão dos livreiros, para o brasileiro ou para parte dos brasileiros, a forma de compra do livro virtual é realizada há poucos anos.

Existiria, para parte desses internautas, na visão dos livreiros da cidade, um descrédito relacionado à segurança da compra envolvendo o pagamento com cartão de crédito e, até mesmo, a garantia de o produto ser entregue como firmado na hora da compra, e em bom estado de conservação. Segundo os livreiros caxienses, o brasileiro também gosta de ouvir a sugestão do vendedor e do livreiro sobre a obra procurada. Isso faria uma grande diferença. Todos os entrevistados afirmaram não acreditar no fim do livro, embora o assunto, segundo eles, volta e meia, ser mencionado pela mídia brasileira com opiniões diversas de estudiosos em reportagens e ações que tentam diminuir a presença física do livro adquirido próximo à casa do leitor.

\section{CONSIDERAÇÕES FINAIS}


A comercialização do livro, em Caxias do Sul, como em outras cidades brasileiras, sem dúvida, foi afetada pela chegada das novas tecnologias e do advento da venda através da internet, a partir do final dos anos 1990. Na pesquisa aqui desenvolvida com os livreiros, a manifestação negativa refere-se à concorrência e à deslealdade de mercado entre livrarias físicas e virtuais. Grandes redes de livrarias com franquias distribuídas em diferentes cidades do país, com presença também em Caxias do Sul, comemoram as vendas na internet pois, com maior competitividade, têm um saldo positivo no faturamento. As livrarias menores, presentes como empresas locais (microempresas), por exemplo, sentem a competitividade desleal do processo em pleno mercado. Para elas, a venda do livro físico na internet é o principal inimigo.

O fato de parte das livrarias localizadas em Caxias do Sul ter apresentado uma baixa entre vinte e trinta por cento no final do mês nas vendas dos livros físicos, por causa da concorrência com as livrarias virtuais, pode ser considerado um percentual alto em relação aos índices apresentados em outras cidades, onde os percentuais negativos chegam a apenas dez por cento das vendas ao mês.

Se a crise estabelecida no país em relação ao momento econômico e financeiro não avista um desfecho próximo, o mercado livreiro caxiense já se depara com a baixa procura de títulos em razão dos preços, e pior, com uma crise voltada à diminuição no consumo da leitura e da procura pelo livro. O preço das publicações ainda não é o melhor e mais acessível à grande parte da população. É sentida na cidade, além disso, a falta de políticas favoráveis à propagação do gosto pela leitura e pela procura mais frequente do livro pelo sistema educacional municipal.

Ouvindo os livreiros, também é perceptível que a cadeia do livro passa por um momento de tensão, tornando-se cada vez mais desacreditado. Os livreiros relatam as dificuldades para se manterem de portas abertas. Por isso, utilizam outras estratégias para que o orçamento seja completado. Em Caxias do Sul, alguns estabelecimentos transformaram a livraria em espaço para outras atividades, agregando uma papelaria, uma banca de revistas e até cafeteria. Essa última contribui para a organização de saraus literários, em que a leitura de obras é ligada à possibilidade de comercialização de títulos. O sabor de um chocolate quente no inverno gaúcho ou o cheiro de café parecem melhorar o ambiente em torno do livro, ao menos por alguns momentos.

Do nosso ponto de vista, o comércio livreiro local precisa estar mais próximo do leitor e do que ele quer ter em mãos. Isso passaria pelo desenvolvimento também de um mercado editorial local mais forte e promissor, com a formação de novos leitores e o aumento da confiança dos leitores já formados. Para a constituição desses leitores, são necessárias atividades envolvendo as próprias livrarias e a Secretaria Municipal de Educação, com eventos promocionais nas escolas e na Feira do Livro. É imprescindível uma ação mais direta entre a cadeia do livro na cidade, começando pelo diálogo e fortalecimento de parcerias com órgãos públicos e privados. Por isso, se a base local de livrarias estiver apta ao atendimento comercial de solicitações do mercado escolar, acadêmico e literário, com vistas ao público caxiense e regional, ela convencerá o leitor de que, perto de casa, próximo da rua em que mora, é possível encontrar um bom livro para uma boa leitura. 


\section{REFERÊNCIAS}

ALVES, E. A. Convergência digital e o futuro do livro. 2010. 220 f. Dissertação (Mestrado em Letras) - Pontifícia Universidade Católica do Rio de Janeiro.

CHARTIER, R. A aventura do livro: do leitor ao navegador. São Paulo: UNESP, 1998.

DARNTON, R. A questão dos livros: passado, presente e futuro. São Paulo: Companhia das Letras, 2010.

ESCARPIT, R. A revolução do livro. Rio de Janeiro: FGV, 1976.

GOMES, C. B. Entrevista oral com o presidente da ALCA. Associação dos Livreiros Caxienses, ALCA, Caxias do Sul. Entrevista concedida a Tales Giovani Armiliato em 20 de julho de 2017.

HALLEWELL, L. O livro no Brasil: sua história. São Paulo: EDUSP, 1985.

LÉVY, P. Cibercultura. 2. ed. São Paulo: Ed. 34, 2000.

MARTINS, W. A palavra escrita: história do livro, da imprensa e da biblioteca. 2. ed. São Paulo: Ática, 1996.

MELO, M. A. M. F. de. O Comércio eletrônico e as novas formas de informação: do livro convencional ao livro eletrônico (ebook). 2002. 244 f. Dissertação (Mestrado em Inteligência Aplicada). Florianópolis: Centro Tecnológico, Universidade Federal de Santa Catarina, 2002.

MORAES, R. B. Livros e bibliotecas no Brasil colonial. 2. ed. Brasília: Briquet de Lemos/Livros, 2006. 